\title{
ARTIGOS
}

\section{A TRAVESTI DA IVA E SUAS HISTÓRIAS: A ESCOLA COMO ESPAÇO DE DIAGNÓSTICO E O CONTEXTO DAS CIDADES PEQUENAS}

Waldyr Barcellos Junior ${ }^{1}$

Resumo: Esse trabalho tem como recorte as possibilidades de promover e valorizar a voz das travestis do interior e suas experiências em um contexto que promove o diagnóstico e rotula suas vivências. Leva-se em conta que para os estudos de gênero, as cidades pequenas ou contextos interioranos são um terreno fértil para ampliar as discussões e mostrar outros caminhos da ciência. Essa história se passa no município de Miracema - RJ, no interior do estado, cidade tem 26 mil habitantes atualmente. Nessa pesquisa foram utilizados recursos da antropologia social como observação participante e também ferramentas metodológicas da história oral, com o objetivo de valorizar vozes e ritmos do cotidiano das cidades pequenas e observar a como loucura e a escola promoveram de rótulos na existência.

Palavras-Chave: Escola; Travesti; Loucura; Cidades pequenas.

"Eu assumi minha verdade dentro de uma mentira"

Chica da Iva

\footnotetext{
${ }^{1}$ Mestre em Ensino - Universidade Federal Fluminense - UFF. Mail: waldyr_barcellos@hotmail.com
} Vol. 02, N. 01, Jan. - Mar., 2019 - www.revistas.unilab.edu.br/index.php/rebeh 


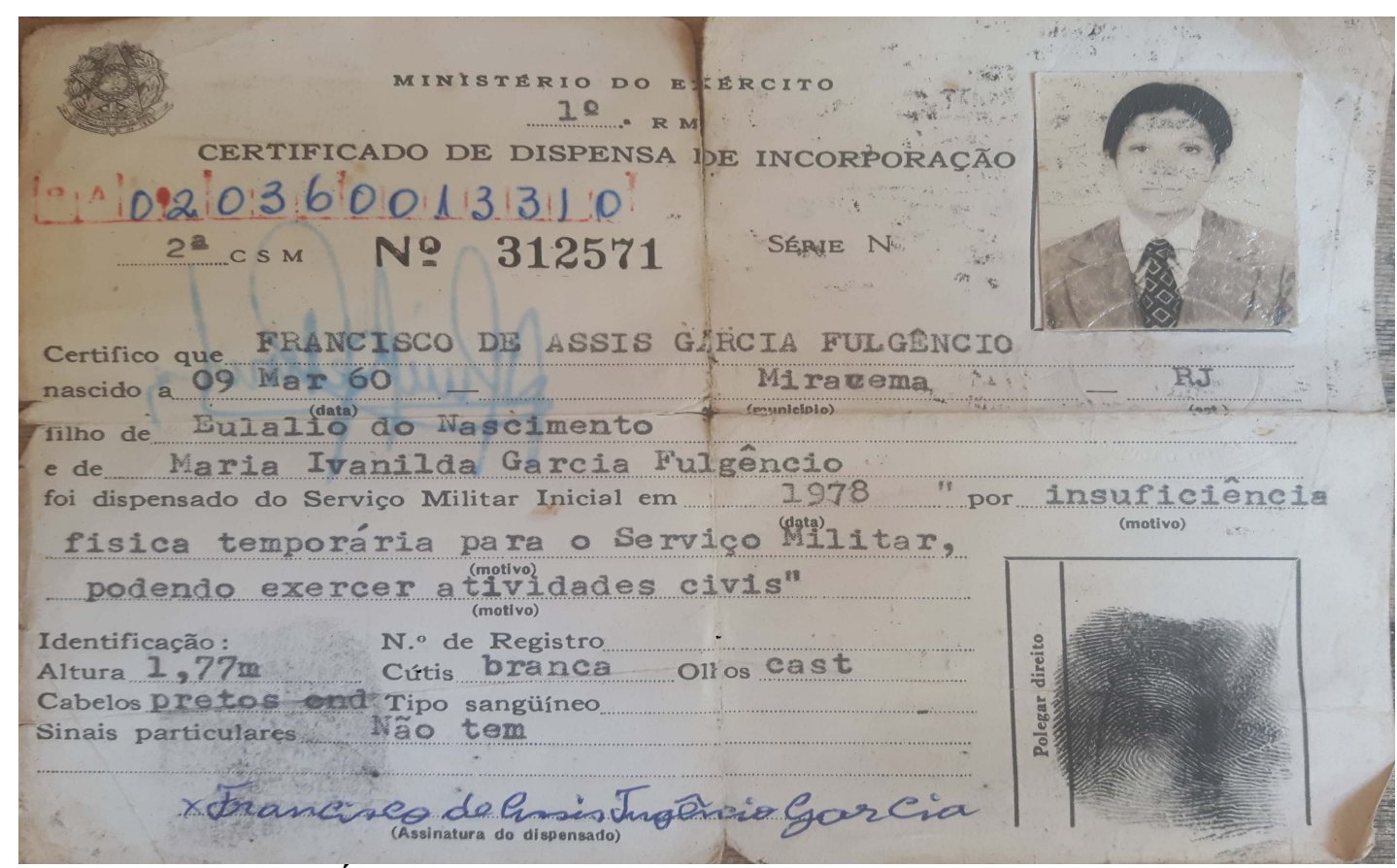

Figura 1 - Única foto de menino: Certificado de Alistamento militar

Fonte: Acervo pessoal ${ }^{2}, 2019$.

O trabalho tem como proposta ouvir a história do outro, dentro do seu cotidiano levando em conta os estudos de Michel de Certeau (1994), que acredita nas possíveis invenções que o ser humano pode fazer em diferentes contextos. Ter um trabalho que não anuncia a capital ou as grandes cidades como protagonistas. Tentando a todo o momento incentivar essa escrita do interior e suas histórias. Percebemos, assim, que o interior é o lugar de grandes revoluções e não só de histórias baseadas na elite, catástrofes naturais e políticos famosos. A proposta é contar sobre histórias ordinárias. Logo se parte da ideia que precisamos dar vozes à experiência que historicamente tem se tornado invisível e também dar chance de pessoas que causaram fissuras no imaginário de pequenos lugares terem suas histórias relatadas. Esses relatos podem ser de grande contribuição para se pensar outros lugares como alvo de estima e pesquisa.

${ }^{2}$ Chica apresentou o acervo de fotos que não era previsto na entrevista e também solicitou que seu nome fosse mantido. Pois ela sentia necessidade de que suas vivências fossem aproveitadas, e futuramente, quando o trabalho fosse apresentado ou publicado, ela queria que as pessoas da cidade soubessem noção que alguém se interessara por suas histórias. Assim, com termo de esclarecimento assinado, foi mantido o nome e as fotografias.

Vol. 02, N. 01, Jan. - Mar., $2019 \cdot$ www.revistas.unilab.edu.br/index.php/rebeh 
Essa história pretende contar e ampliar os contextos de cidades pequenas e gênero com a proposta de fortalecer esse campo na dimensão política e suas ansiedades. Temos como identificação fortalecer novos caminhos que a história tem pretendido com as demais ciências humanas a percorrer, com o objetivo de valorizar narrativas de vida em escola ou escola da vida, onde outros discursos se estabelecem e talvez se reorganize. São formatos nada convencionais de existência, tendo como política, viver e relembrar essas trajetórias tão diferentes, que implicam desafio muito grande de mergulhar nessas memórias podendo produzir uma sensação de deslocamento, em que a riqueza dessas trajetórias nos ensina de como a escola e seus rótulos promoveram certos padrões de abandono, ausências e interrupções. Esse corpo que hoje é um corpo revisitado através de lembranças nos ensina como a escola ainda tem produzido pouco interesse em pessoas que discordam (LOURO, 2015). Ensina ainda que as trajetórias, mesmo em diferentes tempos e datas, têm todo um contexto comum.

Chica de certa forma queria falar de outros locais, a escola vai aparecer depois de todas as outras vivências e lembranças, por vezes eram o assunto mais rápido apresentado nas entrevistas. As histórias ou trajetórias escolares era o assunto mais tímido e vergonhoso; os outros assuntos como: uso de hormônios, silicone, prostituição, são os assuntos comuns, falados com naturalidade e sem constrangimento. Os amores impossíveis e casos noturnos. Tudo nessa narrativa tem um grande ar de fantasia e histórias longas (KOFES, 2001).

Esta entrevista aconteceu no trabalho e na pesquisa da minha dissertação de mestrado. Na verdade, não estava prevista e acabou proporcionando grandes surpresas. Seria uma história meio esquecida no meio da cidade, de uma travesti que não elegeu na vida o sofrimento como caminho. Hoje, apesar das dificuldades tem uma vida estabilizada. Quase nunca é vista na rua, viaja muito para casa de parentes. Não se monta e sempre reclama dos cabelos que vem caindo com a idade. Mora em uma casa amarela depois de uma escadaria, numa espécie de "beco" onde fica boa parte do tempo. Perto de completar seus 58 anos, atualmente mora sozinha em sua casa com um grande quintal, com muitas plantas e pés de manga.

Neste primeiro contato, explicamos sobre o trabalho, quais as pessoas que tinha entrevistado, o que a deixou feliz e agradecida por ter sido convidada a fazer parte do

Vol. 02, N. 01, Jan. - Mar., 2019 - www.revistas.unilab.edu.br/index.php/rebeh 
trabalho, me convidou para entrar e ir ao quintal, pois era parte mais fresca da casa e fazia muito calor. Sentamos, e ela disse que poderia perguntar começamos a conversar e me disse que ia buscar umas fotos então me mostrou sua única recordação de menino. Disse que se tratava do alistamento militar, situação em que foi obrigada a se apresentar de terno, e que foi a única vez que vestiu roupa parecida. Ainda conta que não conheceu o pai vivo, que foi criada pela sua mãe a qual sempre teve um bom relacionamento e que aos 9 anos falou para ela que queria ser uma menina. Aos 12 começou a tomar alguns hormônios, mas logo largou o tratamento, pois sentia efeitos colaterais e disse que na sua época não enfrentou grandes barreiras; "tinha duas reações, as pessoas tinham medo/espanto ou respeito." Contou histórias de uma época que nunca imaginei. Tentamos compor um quadro sobre suas vivências e a escola/loucura. Logo na primeira pergunta sobre o tema ela afirma; "Odiava a escola, ia para merendar e fazer bagunça... era um capeta, para ser sincera, terminei o primário muito mal”. Tinha como afirmação que a escola não era espaço para ela, ou melhor, para muitos; "Na minha época pobre não ficava na escola, professor não gostava da gente... ninguém terminava”. E ela acreditava que não tinha identificação com os estudos; "Único dom que Deus me deu foi a cozinha. Eu sei fazer vários pratos, trabalhei muitos anos em cozinhas de restaurantes". Dessa forma, ela afirma que nunca sentiu vontade e interesse de estudar, que as coisas foram acontecendo em sua vida de forma muito "mágica". Para ajudar sua mãe precisava trabalhar, mas para travesti era muito difícil. Acabou indo para Rio de Janeiro e todo mês vinha a Miracema- RJ. Logo começa a contar os reais motivos de não ter ficado em Miracema:

"Tinha um policial que fazia muita covardia com as meninas. Vê se pode, não queria me deixar sair de mulher a todo o momento me parava e também minhas amigas, era dificil, tinha bicha que apanhava. Eu nunca apanhei... (risos) na verdade podia vir me bater, mas eles também iriam sair perdendo. Acabei me envolvendo em muita confusão, minha mãe ficava nervosa com medo de acontecer alguma coisa comigo. Eu era nervos, considerada louca... depois que tomava meus Otis... transformava [referente à bebida alcoólica].”

Nesses relatos Chica sempre apresenta a figura da loucura como parte da sua personalidade, era tida como explosiva e ao mesmo tempo reforçava que essa loucura Vol. 02, N. 01, Jan. - Mar., 2019 - www.revistas.unilab.edu.br/index.php/rebeh 
era oferecida pela visão das pessoas e pela sociedade da época. Que acreditava na travesti como um ser "Desnatural e quase mitológico" uma representação de um monstro indefinido.

Ela associa sua aprendizagem à rua como seu campo de formação, com outras travestis da época que acabaram iniciando em todo esse processo de experimentar uma construção do desejo e de se aproximar do feminino. Ela afirma que ficava no mercado municipal, que era o centro comercial. Foi ali que nasceu a "Chica da Iva”:

"Esse nome quem me deu foi o povo... Todas tinham nomes e sobrenomes estrangeiros, eu era a Chica, a filha da dona Iva, eu nunca mudei de nome." Sobre seu nome, tem muito orgulho, a todo o momento relata que as amigas do seu tempo mudavam de nome sempre, como estratégias de sobrevivência. Ainda afirma que muitas meninas do interior tinham suas rivalidades, mas também ajudavam umas às outras.

O mercado municipal fica localizado numa rua atrás do que hoje seria a "Rua Direita", que é o centro comercial de Miracema. Chica conta que aos poucos foi se vestindo de mulher e também ficava por outros períodos “desmontada”. Na rua que hoje é o centro da cidade, nenhuma travesti podia andar, então só ficavam na rua atrás, onde era o mercado municipal. Tinha todo um território a qual parte das meninas poderia andar. Chica afirma que não pegou nenhuma cafetina, quem comandava era a polícia, ela afirma que ficava em um bar "Não me sentia prostituta, pois fazia muito de graça, naquela época no auge da juventude... (risos) eu queria aproveitar, também cobrava era lógico, porque não sou trouxa, agora tinha axé [sorte] para pista”. Chica conta que ficou famosa quando a associaram a primeira cafetina do local, mas que na verdade ela que se revoltou com um policial e acabou organizando as meninas que eram exploradas e assaltadas pela própria polícia. Chica afirma que só teve essa experiência em Miracema, que quando saiu daqui foi para trabalhar e um grande restaurante.

"Bicha eu era terrível na escola, muito bagunceiro era um menino atentado, odiava tabuada era tudo decorado. Viiiiiiiiiadoooo, uma coisa horrorosa, os recreios separados. Todos os livros eram comprados na minha época... Era assim: E Tinha condições de comprar livro estuda, não tinha ou copiava tudo na mão ou parava de estudar, a escola nunca serviu para nada. Já era viado, minha vida já tava toda

Vol. 02, N. 01, Jan. - Mar., 2019 - www.revistas.unilab.edu.br/index.php/rebeh 
ferrada... não tinha sentido escola de forma nenhuma. Quem formava continuava desempregado, só se fosse filho de rico. Outra coisa: tinha uma carteirinha maldita que carimbava se você chegou atrasado. Todo mundo gostava de fugir daquilo, eu pulava muro, barranco era assim." A escola se torna um lugar de fuga e de rótulos, onde Chica nos apresenta este local em suas lembranças como um lugar que muitas pessoas estavam dispostas a sair, mesmo que isso fosse decepcionante para sua mãe que acreditava que a escola era um local de "Dar jeito nas pessoas". Chica ainda fala de como se sentia incomodada pela escola remeter a um local disciplinador, criticando as cores e o extremo ritual religioso na escola: "nos queriam que comportasse como santos... Como? Eu era um capeta/louca?”. Chica ainda afirma que a escola não era um espaço encantado e todo mundo tinha rótulos, ela confirma que a escola que denominava em seus discursos a loucura acompanha a sua vida até os dias atuais, e que os comentários referentes a ela por muitas vezes eram cruéis. "Esse menino diferente não vai aprender ele é filho de lavadeira, essa gente é louca não sei o que faz na escola”. Eram frases como essa que Chica afirma ter escutado dentro do contexto escolar por diversas pessoas, o que mostra como a pobreza é associada à loucura.

"As escolas não tinham cor era tudo cinza, os uniformes deveriam ser impecáveis... os meus eram porque minha mãe lavava roupa para fora. Os professores tinham horror de pobre, chamavam todo mundo de burro, louco, puxava orelha e também beliscão debaixo das axilas, aquele local foi dando uma sensação ruim, vivia com dor de barriga. Acredito que ao sair da escola eu queria mesmo era radicalizar nunca fui fácil. Outra coisa, viadinho apanhava todos os dias e também sofria abuso e ninguém na escola ficava do nosso lado. Nunca no período que eu fiquei recebi um elogio ou alguém tomou alguma atitude para ajudar. Então bicha, virei demônio! Eu batia muito também, tampava [jogava] pedra nas janelas da escola... e era um babado, desde cedo a escola me olhava como marginal... acabei sendo."

A escola além de reprodutora promovia o sentimento de não pertencimento, a que fragilizava as lembranças de Chica. E era um assunto que deveria ser o centro e que acabou promovendo outros tipos de escolarização fora desse contexto chamando escola. As dificuldades (desde muito cedo ser considerado um menino louco e futuramente uma louca enquanto travesti) marcam toda narrativa da entrevistada, que reforça que a escola

Vol. 02, N. 01, Jan. - Mar., 2019 - www.revistas.unilab.edu.br/index.php/rebeh 
era um ambiente extremamente ruim onde viveu experiências que fragilizavam a saúde mental e também a sua trajetória escolar.

Os aspectos que estão de alguma forma cruzando essas fronteiras de gênero e mostrando múltiplas construções históricas ligadas ao ensino de pessoas que não tiveram oportunidade de permanecer nesse modelo de escola, estabelecido para satisfazer um ensino pautado na submissão de múltiplos fatores culturais. De maneira que condiciona as pessoas travestis pensar a escola e seus fracassos, a partir de inadequações promovidas por seus corpos comprometendo a sua saúde mental. Chica nos leva a pensar: que histórias da educação promovemos? Valoriza quais atores? Quem pode pensar a escola? Escola e saúde mental devem estar associadas? Todo esse rico depoimento nos mostra que a educação, principalmente no Brasil, não deu espaço para debates necessários. Por isso nos atentamos a uma grande resistência ao tema escola quando abordado com as entrevistadas.

Assim, o contexto escolar, num primeiro momento, é tido como sem importância para elas, apesar de termos visto que, com o passar dos encontros, a escola surge como lugar de muito sofrimento e exclusão. Isso gera muitas inquietações sobre esse modelo educacional pensado sobre as pessoas, nunca numa relação de alternância, onde as pessoas atendidas no contexto escolar possam pensar práticas e propor novas alianças didáticas. Tornar a escola um espaço atraente e algo que percebemos que não estava na pauta, na verdade o objetivo realmente foi formar alianças para que as pessoas se sintam deslocadas e culpadas por ter abandonado o contexto escolar.

As sociedades urbanas, no entanto, ainda apostam muito na escola, criando
mecanismos legais e morais para obrigar que todos enviem seus filhos e filhas
à instituição e que eles ali permaneçam alguns anos. Essas imposições,
mesmo quando irrealizadas, têm consequências. Afinal, passar ou não pela
escola, muito ou pouco tempo, é uma das distinções sociais (LOURO, 2015,
p. 21).

Chica ainda se sentia um pouco culpada por não ter permanecido no contexto escolar, afirmando que poderia ter resistido, mas que não quis, preferiu ir para cidade grande trabalhar. Afirma que muitas famílias naquela época davam maior importância ao trabalho porque acreditavam que a vida na escola não era compatível para pessoas pobres. Ainda relata as dificuldades que passou ao deixar o interior e traz na lembrança de que foi a primeira travesti a colocar silicone. "Subi no ônibus e desci montada".

Vol. 02, N. 01, Jan. - Mar., 2019 - www.revistas.unilab.edu.br/index.php/rebeh 
Disse que foi um maior alvoroço no seu bairro onde é a figura mais conhecida e famosa. Chica mora em um bairro que tem o apelido de Capivara "Eu era a rainha da Capivara". Ao longo da entrevista surge o que seria para Chica uma travesti. Para entrevistada, foi um objetivo alcançado com muita dificuldade, toda uma vida se tornando e investindo em ser travesti "A gente nunca para,todo dia era uma montagem... tem que ter investimento, eu como sempre fui pobre tinha que trabalhar com o que tinha. Colocar para jogo o meu melhor”. Ela explica como se considera depois de passar uma vida inteira tentando está no feminino. Ela também observa que ser travesti e mulher dá o mesmo trabalho, "Mulher também se monta".

"A travesti para mim é o engano... O que atraia os homens era esse ar de engano. Também era sua justificativa, tipo pegou por engano. Então nós, travesti, trabalhamos com o engano, nunca quis ser mulher como também nunca fui homem. Então, bicha, o engano era bom para eles muito mais que para gente, por isso ninguém casava com travesti por ali acabava o engano e as que casaram nossaaaa... como sofreram. A loucura era algo nítido e todas travestis da época, a sociedade nos via assim como algo que não pudesse existir, muitas foram parar em Manicômio pois a familia internava. Era triste pois, depois que saía a bicha, saía mais doida que entrou. Eu vi isso tudo acontecer e outras violências até que um dia passei a retribuir".

Essa parte da entrevista nos mostra como cada pessoa percebe seu gênero, como cada visão tem sua definição própria ou não tem definição. Ao mesmo tempo em que percebemos que existe um modelo pelo qual elas, por muitas vezes, são forçadas a se apropriar. Também observamos uma invenção própria com significados únicos e muito individuais, isso é percebido também dentro do contexto escolar, as experiências são muito pessoais. Para o trabalho é muito importante valorizar os espaços de cada momento na vida de pessoas travestis em cidades pequenas. Esse processo de passar pela escola carrega um conjunto de importância ou sem importância que vai sendo relatado ao longo da entrevista. O que observamos é que neste contexto existe uma mudança repentina em Chica quando vai mencionar a escola em seus relatos. E em alguns momentos com certo desanimo, muitas perguntas ficam sem repostas, muitos detalhes não são ditos. Sobre outras lembranças, Chica gosta muito de contar e revistar a memória. Tem muitas saudades da mãe da qual cuidou até falecer. Também acha que

Vol. 02, N. 01, Jan. - Mar., 2019 - www.revistas.unilab.edu.br/index.php/rebeh 
tudo teria sido diferente se seu pai estivesse vivo, quando estava na fase de transição. Ela afirma que sua vida foi um grande desafio a qual teve que pagar por eles. "Ser travesti está ligado ao preço do desafio... depois muita coisa muda. Acabamos nos arrependemos de muita coisa."

E essa parte da entrevista parece um desabafo das dificuldades, observamos uma solidão em sua fala; conta que anos depois voltou para outro tipo de escola na qual as dores foram bem grandes que duraria por 6 meses. Ela afirma que era um local onde as pessoas eram depositadas e tudo que você é se esvazia. Também relata o sentimento de abandono por parte dos familiares e os caminhos de solidão que a vida vai tomando. Ela relata que não se sentia humana; nesse momento da trajetória, ela afirma que foi o lugar que ela mais aprendeu através da dor e do abandono. Abaixo Chica relata o motivo:

"Nunca fui fácil, você, mona, fica me perguntando sobre escola e aprendizagem, então tem um lugar que eu aprendi demais foi na CADEIA. Mas deixa te contar o motivo... eu era muito nervosa... Então, eu e falecida Paullety do Cruzeiro fomos tomar banho de rio com uns homens, passamos a tarde toda namorando e fazendo os babados e tal. Ele muito amoroso comigo, me iludindo eu deixando... melhor da vida é ilusão, enquanto você está enganada você está feliz, quando descobre a vida vira uma verdadeira desgraça. Bom, então eu fui subindo para minha casa já por volta da 18 horas e marquei com as meninas no mercado municipal, eu passava por trás da rua da igreja matriz, vinha costurando a rua porque travesti não podia passar em qualquer lugar. Quando cheguei a mercado o cara que estava comigo, estava sentado com umas putas eram mulheres e começaram a debochar de mim, falando mal de viado e tal... até que cheguei à mesa perguntei a ele qual foi? Porque ele estava fazendo isso, se ele tinha passado a tarde toda com meu piru na boca. Bicha... desgraça anunciada, ele começou a me bater como eu estava de salto cai, quando eu levantei estava sem salto de cabelo amarrado, juntei ele de pancada, mas muita bordoada, por fim outro cara veio também... nisso eu peguei uma garrafa e cortei ele... fui parar na cadeia"

Nesse momento vejo um grande arrependimento por parte da entrevistada no sentido que a vida de uma travesti do interior é muito mais complicada do que eu realmente poderia imaginar, ou melhor, formular hipóteses. Era como Chica se sentia em contar essa parte da história, era uma fala agitada misturada com revolta. "A cidade

Vol. 02, N. 01, Jan. - Mar., 2019 - www.revistas.unilab.edu.br/index.php/rebeh 
inteira fode com sua vida... o dia que você decide revidar, você é agressiva”. Percebo em suas colocações que nossa entrevistada teve uma juventude a qual resistia às múltiplas dificuldades sozinhas. "Eu não deitei e não dormi para vida". E ao mesmo tempo passou muita coisa sozinha sem o apoio da família, sempre enaltecendo a figura da sua mãe, mas relata que nos piores momentos ela já não estava mais viva para lhe defender. "A única pessoa que vai te defender é sua mãe... o resto da família,só se você tiver dinheiro". Os relatos sobre essa parte da sua vida nos mostram a verdadeira necessidade dela ter que deixar a cidade. Ela ficou seis meses presa sem visita e também "sem compra" (ser receber comida das visitas), teve que aprender a se virar na cadeia. “Quando cheguei à cadeia conheci outras travestis todas de cabeça raspada e de peito. Uma das travestis disse: os meninos já sabem da sua chegada, case com um senão vai ser pior".

"Bicha... na cadeia é assim ou você casa com dono da cela ou tem que dar para todos, e o pior, dar de graça”. A entrevistada começa a relatar que para ela esse período foi uma grande escola, que deve isso à cadeia, acreditando que ela banalizava a escola. Foi nesse período que sentiu falta do contexto escolar que poderia ter salvado seus caminhos na vida, assim ela depositou suas esperanças de sair daquele lugar lembrando sempre como tudo poderia ter sido diferente se tivesse estudado. Ou refletiu sobre esse espaço, acreditando nas dificuldades e no arrependimento de não ter estudado e que esse fato levou a essa punição, e assim pensava "Eu estava na cadeia porque não estudei”.

"Só lembrei-me da escola, mona quando estava presa, foi a primeira vez que li um livro na verdade um romance sem capa, pois me ajudava passar o tempo, era naquele formato de Julia, Bianca e Sabrina, eu acho que chamava... hum... Duelo sobre o Sol - Anne Weale, então naquele momento eu lembrava com arrependimento da oportunidade de estudar, talvez eu tivesse outro destino. Todas as minhas amigas que tinha batido na cadeia contavam história de desejo que foram bem recebidas. Travesti gosta de mentir (rindo), lógico depois que sai de lá contei muitas mentiras falei que tinha adorado que tinha arrumado um bandido, assaltante de banco rico, moreno vindo da Paraíba, tudo uma mentira, eu arrumei foi um homem feio sem dente que tinha sido preso por roubar galinha e comida para não morrer de fome. Os homens mona eram

Vol. 02, N. 01, Jan. - Mar., 2019 - www.revistas.unilab.edu.br/index.php/rebeh 
todos piolhentos não tinham ninguém rico no meu pavilhão, só tem pobre na cadeia porque eu desci para Rio, acho que chama Água Santa o nome do presídio”.

Dessa forma podemos observar que a escola é lembrada com outros significados. Chica acredita que a culpa foi dela por ter abandonado o contexto escolar e ao mesmo tempo conta os rituais que passou na escola. Relata a vontade de fugir das aulas e a percepção de como o ensino era totalmente tradicional, de que era obrigada a rezar no altar de santos. "Naquela época tinha um altar perto da sala da diretora, colocava de castigo ali ajoelhada e rezando, a escola também não deixou de ser cruel... eu acho que pobre só aprende apanhando ou sendo castigado”. Com um olhar de sofrimento Chica chega às suas conclusões sobre a vida e recorda como foi injustiçada, ao ponto de acreditar que ela era a promotora dessas escolhas e que a falha era dela, por não ter se adequado a vida e não ter respeitado as normas.

Desaprendemos com ela a visão romântica da escola e prestamos muito atenção no atravessamento de classe social em sua fala. Percebemos como a pobreza está a todo o momento cercando a sua vivência e também fomentando um debate dessa escola que ainda produz um horror a pobreza, como fosse pecado ou crime. Chica vem relatar um catolicismo exagerado que permanece até hoje nas escolas, na oração do Pai Nosso na hora da entrada, também espalhados nas paredes a imagem de Cristo na cruz. Todo o relato as lembranças estão ligadas a punição ou correção que é levado em conta por ela, suas lembranças estão totalmente ligadas a fatos já denunciados pelo mito do estado laico, que ainda continua reproduzindo discursos altamente desadequados para quem realmente precisa da escola como política pública. Dessa forma percebemos no relato da entrevistada uma identidade transitória, ela fala da convivência do mundo dos homens e também de todo seu esforço para se aproximar desse feminino desejado.

"Não me peça definições. Eu me sentia mulher às vezes e depois me sentia homem, era tudo assim...". De forma simples, Chica tenta nos mostrar que para se entender uma travesti as definições podem ser um caminho arriscado, porém assumimos nossa inclinação, tendência e vontade de se apropriar das definições ou categorias históricas. Queremos tentar entender aquilo que talvez não tenha entendimento, “Travesti é um deboche”.

Vol. 02, N. 01, Jan. - Mar., $2019 \cdot$ www.revistas.unilab.edu.br/index.php/rebeh 
Acreditamos que Chica zomba, através de sua trajetória, desse modelo de gênero e da vaga ideia de uma identidade de gênero fixa (BUTLER, 2003). Um constante movimento de devir onde mora ambiguidades entre os universos masculinos e femininos, assim as travestis treinam para usar os repertórios femininos e seus discursos como também seu vestuário e beleza. Chica tem na sua história, múltiplas experiências que a ajudam a elaborar suas linhas de defesa e desconstruir muitas determinações. Uma dela por estar viva, visto que a média de vida das travestis e bem baixa no Brasil (BENEDETTI, 2007). "Eu não era a mais bonita, mas sou a única que estou viva". Chica se orgulha de ter passado por tudo e ainda estar viva para contar suas histórias e relevar todas as fragilidades do universo das travestis desse contexto do interior que pelo visto e muito mais agitado do que poderíamos imaginar (SCOTT, 1998).

"Mona eu era ex-presidiária, travesti louca e não tinha estudo, eu coloquei a cabeça no lugar e fui embora com emprego arrumado, morta de medo da reação das pessoas por nunca ter visto travesti empregada, tinha dificuldade de leitura mais tinha ganhado mais experiência com livros os romances que lia na cadeia... Então, bicha, eu comecei a trabalhar na casa de uma atriz de teatro que se chama Sônia Dutra. Lá eu tive oportunidade de me aproximar de outras travestis, inclusive a Rogéria que era amiga da minha patroa, eu fui muito bem recebida... Ali eu fui vendo como era o outro mundo, as possibilidades através do trabalho. Aprendi muito trabalhando com essas pessoas, também tinha saudades de Miracema e sempre voltava. Mas visto que em Miracema já tinha me envolvido em diversos babados, funcionou o Rio de Janeiro como um descanso. E todo mundo respeitava as pessoas que moravam fora, as que ficaram aqui sofreram

Figura 2 - Chica

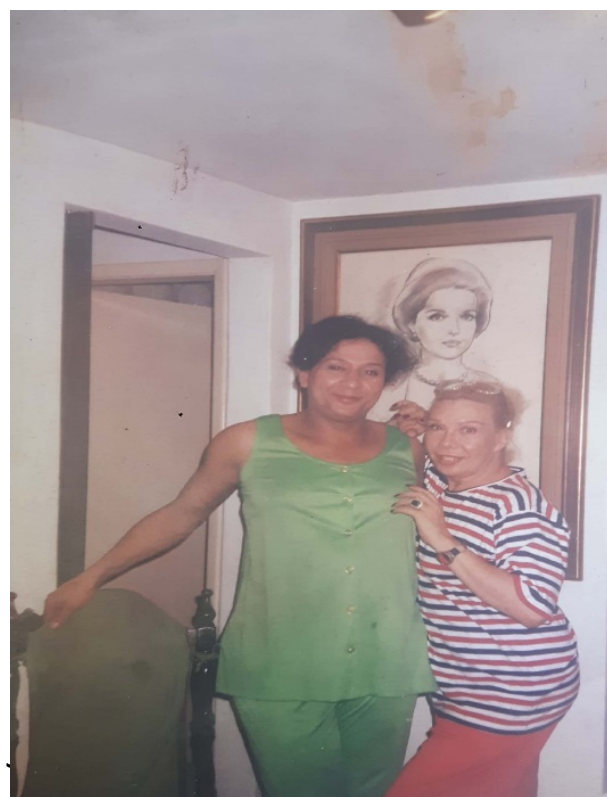
muito". casa em que de Janeiro

Vol. 02, N. 01, com Rogéria na trabalhava no Rio 
Fonte: Acervo pessoal, 2019.

"Bicha vou pegar uma foto que tenho com Rogéria... bicha!Era assim que foi uma parte da minha vida, às vezes olho para trás e desconfio de mim... porque realmente não sei como suportei tanta coisa na vida e ainda estou viva”. Chica mostra sua trajetória com ar de superação, não que ela em algum momento da narrativa passasse um sentimento de vergonha ou medo. No entanto, percebemos em sua trajetória o sentimento de voltar para o interior a qual ela atribui muita felicidade. Pois já tem muitos anos que ela retornou para cuidar de sua mãe e também de um companheiro já falecido, por conta do qual recebe pensão.

"Então eu voltei porque sentia saudades das coisas daqui. Nunca me senti parte do Rio, toda quinzena eu voltava para Miracema, meu velho morava aqui e estava doente, já tem seis anos que se foi, me deixou com sua pensão eu cuidei dele até a morte... Bicha, era um caso antigo, ficamos juntos por vinte anos. Mesmo passando por muitas coisas por aqui, nada melhor que voltar para casa sentir o cheiro do seu lugar e poder escolher seu lugar para morrer, talvez e a única escolha que eu fiz realmente".

Essa é a história de Chica, que passou por uma grande política de rótulos sempre invocada como louca, travesti, pobre e da roça por morar em uma cidade pequena. A loucura atravessa todos os campos da sua vida, na escola principalmente, na mão da polícia segundo os seus relatos. Ela se lembra do passado com muita felicidade, por estar viva e ainda lúcida apesar de toda agonia que passou e acusa o contexto escolar de promover a loucura como maldição. Todas as pessoas que se identificam como travestis em cidades menores, o nível de resistência tem que ser maior, pois as dificuldades são

Vol. 02, N. 01, Jan. - Mar., 2019 - www.revistas.unilab.edu.br/index.php/rebeh 
imensas. Se olharmos para esse trabalho podemos aprender que além das narrativas, Chica traz nas suas conclusões de vida outros significados para os estudos de gênero, entre eles a importância escutar as vozes de outros lugares, potencializando a existência e suas criações para continuar existindo. Também traz a percepção de como a ausência

de políticas públicas precarizou sua saúde e seu processo educacional e como os rótulos pode acompanhar seu imaginário pela vida toda fragilizando sua saúde e relatando a escola como um espaço de diagnóstico.

\section{Referências}

BENEDETTI, Marcos Renato. Toda feita: o corpo e o gênero das travestis. Rio de Janeiro: Garamond, 2005.

BUTLER, Judith. Problemas de gênero: feminismo e subversão da identidade. Rio de Janeiro: civilização Brasileira, 2003.

CERTEAU, Michel de. A Invenção do cotidiano. Artes de fazer. Petrópolis, Vozes, 1994, [Tradução: Ephraim Ferreira Alves].

KOFES, Suely. Uma Trajetória em Narrativas. Campinas: Mercado das letras, 2001

LOURO, Guacira Lopes. Pedagogias da sexualidade. In: LOURO, G. L. (Org.) O corpo educado: pedagogias da sexualidade. 3 . ed. Belo Horizonte: Autêntica, 2015. p. 7-34.

SCOTT, Joan Wallach. A invisibilidade da experiência. Trad. Lúcia Haddad. Ver.técnica: Marina Maluff. Projeto História: Revista do Programa de Estudos PósGraduados em História e do Departamento de História, PUC-SP. Nº16. 1998. p.297-325

\section{LA TRAVESTI DEL IVA Y SUS HISTORIAS:}

\section{LA ESCUELA COMO ESPACIO DE DIAGNÓSTICO Y EL CONTEXTO DE LAS CIUDADES PEQUEÑAS}

Resumen: Este trabajo tiene como recorte las posibilidades de promover y valorar la voz de los travestis en el interior y sus experiencias en un contexto que promueva el diagnóstico y las etiquetas de sus experiencias. Se tiene en cuenta que, para los estudios de género, las ciudades pequeñas o los contextos interioranos son terreno fértil para ampliar los debates y también mostrar otras formas de la ciencia. Esta historia tiene lugar en el municipio de Miracema - RJ, en el interior del estado, la ciudad tiene con

Vol. 02, N. 01, Jan. - Mar., 2019 - www.revistas.unilab.edu.br/index.php/rebeh 
26.000 habitantes hoy. En esta investigación, los recursos de Antropología social se utilizaron como observación participante y también herramientas metodológicas de la historia oral, con el objetivo de valorar las voces y ritmos de la vida cotidiana de las pequeñas ciudades y observar cómo la locura y la escuela Etiquetas promocionadas en existencia.

Palabras-clave: Escuela; Shemale; Loco; Pueblos pequeños.

Recebido em: 10/01/2019 Aceito em: 03/05/2019 